\title{
Tek taraflı infraserratus bursitte rehabilitasyon: vaka raporu
}

\author{
Mahmut ÇALIK ${ }^{1}$, Defne KAYA ${ }^{1}$, İrem DÜZGÜN²
}

İnfraserratus bursit klinikte nadir görülen ve ihmal edilen bir patolojidir. Skapular kinematiğin değişmesi, skapulotorasik eklem çevresi çevresindeki kasların kuvvetsizliği bu patolojiye zemin hazırlamaktadır. İnfraserratus bursit nedeniyle skapula alt ucunda ağıı şikayeti olan 49 yaşında kadın hasta çalışmaya dahil edildi. Omuz normal eklem hareket açıklığı, ağıı şiddeti, omuz internal ve eksternal izokinetik kuvveti ve aktif eklem pozisyon hissi değerlendirildi. Skapular kinematiği düzeltmek amacıyla 6 hafta manuel terapi ve 6 ay ev egzersizlerinden oluşan bir program uygulandı. Skapula ve omuz çevresindeki ağn azaldı, kassal kuvvet ve aktif eklem pozisyon hissi tedaviden sonra gelişti. İnfraserratus bursitte semptomlara yönelik, manuel terapi ile skapulotorasik ve glenohumeral eklem çevresindeki kasların kuwetlendirilmesini içeren bir fizyoterapi ve rehabilitasyon programı uygulanmalıdır.

Anahtar kelimeler: Bursit, Skapula, Rehabilitasyon, Egzersiz.

Rehabilitation in unilateral infraserratus bursitis: a case report

Infraserratus bursitis is a rare and neglected pathology in the clinic. Decreased scapular kinematics and weakness of the muscles around the scapulothoracic joint lead up to this pathology. A 49-year-old female patient with a pain complaint at the lower end of the scapula due to infrasratratus bursitis was included in the study. Normal range of motion of the shoulder, pa in severity, internal and external isokinetic strength of the shoulder, and active joint position sense were evaluated. A program consisting of 6 weeks of manual therapy and 6 months of home exercises was applied to correct scapular kinematics. The pain around the scapula and shoulder decreased, muscle strength and active joint position sense developed after treatment. A physiotherapy and rehabilitation program should be applied for symptoms in infraserratus bursitis, including manual therapy and strengthening the muscles around the scapulothoracic and glenohumeral joint. Keywords: Bursitis, Scapula, Rehabilitation, Exercise.

1: Üsküdar University, Faculty of Health Sciences, Department of Physiotherapy and Rehabilitation, İstanbul, Turkey. 2: Hacettepe University, Faculty of Health Sciences, Department of Physical Therapy and Rehabilitation, Ankara, Turkey. Corresponding Author: Mahmut Çalık: mahmutcalik1987@gmail.com.

ORCID IDs (order of authors): 0000-0002-1541-7824; 0000-0003-0552-1190; 0000-0001-8102-9590.

Received: December 27, 2019. Accepted: April 11, 2020.

DOI: $10.15437 /$ jetr.665533 
$\mathrm{S}$ kapula çevresinde anatomik olarak iki bursa yer almaktadir: Supraserratus bursa ve infraserratus bursa Infraserratus bursa, serratus anterior ve göğüs duvarı arasında yer alırken, supraserratus bursa ise serratus anterior ile subskapularis kasları arasında yerleşmiştir. ${ }^{1}$ Sinovyal siviyla dolu bu anatomik bursalar skapula hareketleri sırasinda kaslar arasında ve kas-kemik arasında sürtünmeyi en aza indirmektedir. Skapulanın anormal pozisyonu ve üst ekstremite fonksiyonları sırasında kinematiğindeki azalma bu anatomik bursalarda inflamasyona sebep olabilir. ${ }^{1,2}$

Skapula kinematiğini birçok faktör etkilemektedir. Skapular diskinezi, serratus anterior, orta-alt trapez kaslarinda kuvvetsizlik, üst trapez, levator skapula ve pektoralis minör kaslarında aşırı aktivasyon, torakal bölge ve kosta mobilitesinin azalmasının skapula kinematiğini değiştirdiği bilinmektedir. ${ }^{3,4}$ Skapula kinematiğindeki bu değişimin glenohumeral eklem problemlerine de zemin hazırladığ ${ }_{1}$ gösterilmiştir. ${ }^{4}$ Bunun yanında anormal skapular kinematiğin skapula çevresinde yer alan anatomik bursalarda aşırı sürtünmeye neden olduğu bildirilmiştir. Aşırı sürtünme zamanla supraserratus ve infraserratus bursada inflamasyona zemin hazırlamaktadır. ${ }^{1,2,5}$

Literatürde skapulotorasik bursit tedavisinde kortizon enjeksiyonu, bursektomi ve parsiyel skapulektomi uygulamaları tartışılmaktadır. ${ }^{1,2,5,6}$ Skapula çevresi kasların kuvvetlendirilmesine yönelik egzersiz programı ile manuel terapinin etkinliğini gösteren çalışmaya ise rastlanmamıștır. $\mathrm{Bu}$ olgu sunumu, infraserratus bursit görülen bir hastaya uygulanan fizyoterapi ve rehabilitasyon programının sonuçlarını paylaşmayı amaçlamaktadır.

\section{OLGU}

49 yaşında, beden kütle indeksi $21,63 \mathrm{~kg} / \mathrm{m}^{2}$ ve sağ dominant olan kadın hasta biseps tendinopatisi ve infraserratus bursit tanısı ile, omuz ve skapula alt ucunda ağrı şikayetiyle kliniğimize başvurdu. $\mathrm{Bu}$ olgu sunumu için yapılacak olan değerlendirmeler, tedavi yöntemleri ve tedavi sonuçlarının gerektiğinde bilimsel amaçlı kullanılması hakkında hastaya detaylı açıklama yapıldıktan sonra, aydınlatılmış onam formu imzalatılarak onamı alındı. Hasta anamnezinde skapula alt ucundaki ağrının 6 ay önce başladığı, istirahat sırasında ağrısının olduğu, baş üstü aktiviteler sırasında ve sırtını bir yere yasladığında ise ağrı şiddetinin belirgin şekilde arttığını ifade etti. Hasta omuz ekleminin ön kısmında, biseps uzun başının yapıştığı yerdeki ağrının ise 3 ay önce başladığını ve bu nedenle 3 ay önce omuz eklemine enjeksiyon yapıldığını ama ağrının azalmadığını, bunun üzerine fizyoterapi ve rehabilitasyona yönlendirildiğini bildirdi. İki ay önce üç hafta boyunca toplam 15 seans fizyoterapi ve rehabilitasyon aldığını, yapılan tedavilerin omuz bölgesine elektrik stimülasyonu, ultrason ve soğuk uygulama, skapula çevresine sicak uygulama olduğunu bildirdi. Hasta 15 seans sonunda omuz başında ve skapula alt ucundaki ağrısının daha da arttığını ifade etti.

Hastanın özgeçmiş ve soy geçmişinde herhangi bir hastalık öyküsüne rastlanmadı.

\section{Fizyoterapi değerlendirmeleri}

Hastanın skapula ve omuz çevresindeki ağrısı istirahat ve aktivite sırasında görsel ağrı skalası (GAS) ile değerlendirildi. GAS'ın kas iskelet sistemine ait ağrı problemlerindeki ICC (Intraclass Correlation Coefficient) değeri 0,860,88 olarak bildirilmiştir. ${ }^{7}$ Hastanın skapula çevresindeki ağrısı istirahatte $8,2 \mathrm{~cm}$, aktivite sırasında 7,0 cm'ydi. Omuz çevresindeki ağrısı ise istirahatte $3,3 \mathrm{~cm}$, aktivite sirasında 6,7 cm'ydi. Omuz eklem hareket açıklığı her iki omuzda gonyometrik ölçüm ile değerlendirildi (Standard BASELINE® 12-inch plastic goniometer, Model 12-1000, New York). Omuz ekleminin farklı hareketleri için gonyometrik ölçümün ICC değeri 0,94-0,97 olarak bildirmiştir. ${ }^{8} \mathrm{Her}$ iki omuz ekleminde fleksiyon, abduksiyon, iç ve dış rotasyonda limitasyon yoktu. Postür analizi gözlemsel olarak yapıldı ve lumbar lordozda artış, anterior pelvik tilt, kifotik postür, sağ omuz seviyesi daha aşağıda, bilateral skapular kanatlaşma ve să̆ skapulanın daha lateralde olduğu tespit edildi. Gözlemsel skapular diskinezi değerlendirmesinde (ICC: 0,55-0,58) sağ skapulada istirahatte ve omuz elevasyonunda daha belirgin olmak üzere skapular kanatlaşma olduğu gözlendi. Serratus anterior kası için sırt üstü pozisyonda yapılan manuel kas kuvvet değerlendirmesinde skapular protraksiyona 
verilen dirence karşı sağ tarafta kas kuvvetinin $3^{+}$olduğu görüldü. Omuz elevasyonu sırasında skapulanın hareketleri gözlemsel olarak incelendiğinde sağ skapulanın yukarı rotasyon ve posterior tiltinde azalma olduğu gözlendi. Bunun yanında torakal omurganın hareketleri pasif olarak end-feel ile değerlendirildiğinde, C7-T1, T2-T3, T6-T7 faset eklemler ile kosta 1, kosta 2 ve kosta 3'ün hipomobil olduğu tespit edildi.

Her iki omzun $60^{\circ} / \mathrm{sn}$ ve $180^{\circ} / \mathrm{sn}$ açısal hizlarda internal ve eksternal rotator konsentrik kas kuvveti, internal ve eksternal rotator kasların kuvvet hissi ile omuz ekleminin aktif eklem pozisyon hissi izokinetik sistem (IsoMed 2000 D\&R GmbH, Almanya) ile değerlendirildi (ICC: 0,80-0,94). Fonksiyonel değerlendirme için Penn Omuz Skoru kullanıldı. Bu skor 0-100 puan arasında puanlanır ve yüksek skorlar yüksek fonksiyonel aktivite seviyesini ifade eder. ${ }^{9}$

Ağrı, izokinetik kas kuvveti ve aktif eklem pozisyon hissi değerlendirmeleri, hastanın kliniğimize başvurduğu ilk gün, 6.hafta, 6.ay ve 12.ay etkilenmiş taraf olan sağ tarafta yapıldı.

\section{Tedavi protokolü}

Hastanın ilk değerlendirme seansını takiben üç gün sonra rehabilitasyona başlandı. Hasta 6 hafta boyunca haftada 2 gün tedaviye alınd. Tedavide skapula, torakal bölge ve kosta mobilizasyonu uygulandı. ${ }^{10}$ Bunun yanında üst trapezi gevşetmeye yönelik manuel izometrik ve eksentrik eğitim yapıldı. ${ }^{11}$ İlk tedavi seansında serratus anterior, orta ve alt trapez, omuz internal ve eksternal kas kuvvetlendirme egzersizlerinden oluşan ev programı hazırlanarak tüm egzersizler hastaya öğretildi. ${ }^{12,13}$ Dirençli egzersizlerde $O M N I$ Perceived Exertion Scale for Resistance Exercise with Elastic Bands (OMNI-RES EB) skalasına göre belirlenen hastaya uygun yeşil renkli elastik bant (Thera-Band $\AA$, Hygenic Corp, Ohio) kullanıldı. ${ }^{14}$ Egzersizler 8-12 tekrar olacak şekilde verildi. Tedavi ve ev egzersizleri bilateral yapıldı. Ev programının 24 hafta boyunca günde $3 \mathrm{kez}$ tekrarlaması istendi. Hastaya ev egzersizlerini uygulayip uygulamadiğını kontrol amacıyla günlük tutturularak takibi yapıldı. Tablo 1'de uygulanan tedavi protokolü ve ev egzersiz programı verildi.

\section{Tedavi Sonuçları}

Skapula alt ucu ile omuzda istirahat ve aktivite ağrısı tedavi sonunda belirgin şekilde azaldı (Tablo 2). Eksternal ve internal rotatör kas kuvveti tüm açısal hızlarda tedavi sonunda artış gösterdi (Tablo 2). Aktif eklem pozisyon hissi değerlendirmesinde propriyoseptif defisitin azaldığı gözlendi (Tablo 2).

Fonksiyonel aktivite düzeyi 68 puan iken, tedavi sonrasında 97 puana yükseldi. Gözlemsel skapular diskinezide ilk ve son değerlendirme arasında skapular kanatlaşmanın azaldığı görüldü. Omuz elevasyonu sirasında skapular yukarı rotasyon ve posterior tiltte artış gözlendi. Torakal omurganin mobilitesi arttı. Serratus anterior kas kuvveti 5 değerine ulaştı.

Tablo 1: Tedavi protokolü.

0-6 Hafta

- Skapula mobilizasyonu

- Torakal bölge mobilizasyonu

- Kosta 1,2,3 mobilizasyonu

- Üst trapezi gevşetmeye yönelik yumuşak doku mobilizasyonu

Ev egzersiz programı

- Elastik bant ile omuz $90^{\circ}$ abduksiyonda internaleksternal rotasyon

- Wall slides

- $\quad$ İlerleyici şınav egzersizleri (duvarda, masa kenarında, yerde, yumuşak zeminde)

- Yan yatışta dirençli eksternal rotasyon

- Yüzüstü pozisyonda farklı abduksiyon açılarında skapular retraksiyon

- Serratus anterior için farklı açılarda yumruklama, dinamik sarılma egzersizleri

\section{TARTIŞMA}

İnfraserratus bursit gelişen olgumuza bilateral olarak uygulanan 6 haftalık manuel terapi ve 6 aylık fizyoterapi ve rehabilitasyon sonrasında hastanın her iki ekstremitesinde de ağrı, kas kuvveti, aktif eklem pozisyon hissi, fonksiyonel aktivite düzeyinde olumlu yönde değişimler elde edildi.

Literatüre bakıldığında infraserratus bursit, anormal skapula pozisyonu ve skapula kinematiği ile aşırı kullanıma bağlı olarak görülmektedir. ${ }^{1,2}$ Olgumuzda sağ tarafta skapular diskinezi ve serratus anterior kasında 
Tablo 2: Ağrı, izokinetik kas testi ve aktif eklem pozisyon hissi değerlendirme sonuçları.

\begin{tabular}{|c|c|c|c|c|}
\hline & Başlangıç & 6. hafta & 6. ay & 12. ay \\
\hline \multicolumn{5}{|l|}{ Ağrı değerlendirme sonuçları } \\
\hline \multicolumn{5}{|l|}{ Skapula çevresi } \\
\hline İstirahat ağıısı (cm) & 8,2 & 3,1 & 1,2 & 0,7 \\
\hline Aktivite ağrısı (cm) & 7,0 & 2,8 & 1,0 & 0 \\
\hline \multicolumn{5}{|l|}{ Omuz çevresi } \\
\hline İstirahat ağrısı (cm) & 3,3 & 1,4 & 0 & 0 \\
\hline Aktivite ağrısı (cm) & 6,7 & 1,6 & 0 & 0 \\
\hline \multicolumn{5}{|l|}{ İzokinetik kas testi sonuçları } \\
\hline \multicolumn{5}{|l|}{ Eksternal rotasyon } \\
\hline$\left(60^{\circ} / \mathrm{sn}\right)(\mathrm{Nm} / \mathrm{kg})$ & 0,32 & 0,41 & 0,44 & 0,52 \\
\hline$\left(180^{\circ} / \mathrm{sn}\right)(\mathrm{Nm} / \mathrm{kg})$ & 0,22 & 0,28 & 0,33 & 0,39 \\
\hline \multicolumn{5}{|l|}{ İnternal rotasyon } \\
\hline$\left(60^{\circ} / \mathrm{sn}\right)(\mathrm{Nm} / \mathrm{kg})$ & 0,41 & 0,48 & 0,54 & 0,60 \\
\hline$\left(180^{\circ} / \mathrm{sn}\right)(\mathrm{Nm} / \mathrm{kg})$ & 0,30 & 0,41 & 0,48 & 0,52 \\
\hline \multicolumn{5}{|l|}{ Aktif eklem pozisyon hissi } \\
\hline \multicolumn{5}{|l|}{ Eksternal rotasyon } \\
\hline $45^{\circ}$ & 8 & 5 & 3 & 2 \\
\hline $75^{\circ}$ & 7 & 4 & 2 & 1 \\
\hline \multicolumn{5}{|l|}{ İnternal rotasyon } \\
\hline $45^{\circ}$ & 11 & 6 & 4 & 2 \\
\hline $75^{\circ}$ & 9 & 4 & 4 & 2 \\
\hline
\end{tabular}

kuvvetsizlik görüldü. Anormal skapular kinematiğin skapulotorasik eklem biyomekaniğini değiştirdiği ve glenohumeral eklemde birçok patolojiye zemin hazırladığı bilinmektedir.3,4 Olgumuzda infraserratus bursite ek olarak biseps tendinopatisi de vardl. Hastanın şikayetlerine bakıldığında skapulanın inferior kenarındaki ağrı şikayeti kliniğimize başvurmadan 6 ay önce başlamışken, omuz ağrısı ise bu şikayetten 3 ay sonra ortaya çıkmıştı. Bu sonuç skapulotorasik eklemde meydana gelen bu patolojinin biseps tendinopatisine zemin hazırlamış olabileceğini düşündürebilir.

Literatürde skapulotorasik bursit tedavisine yönelik rehabilitasyon protokolü bulunmamaktadır. Skapulotorasik krepitasyon olan bireylerde yapılan çalışmalarda skapula kinematiğinin skapula çevresi kasların kuvvetlendirilmesi, postürün düzeltilmesi ve skapulotorasik eklem çevresi kasların enduransının artırılmasına yönelik egzersizlerin uygulanması gerektiği bildirilmiştir.1,2,5 Skapulotorasik bursitin, skapulotorasik krepitasyona bağlı gelişebileceği söylenmiştir.1,2 Olgumuzda skapular kinematiğin düzeltilmesine yönelik manuel terapi uygulamaları ile birlikte skapulotorasik ve glenohumeral eklem çevresindeki kasların kuvvetlendirilmesine yönelik ev egzersiz programı planlanmıştır. Manuel terapi uygulamaları, skapula, torakal bölge ve kosta mobilizasyonu ile üst trapez gevşetilmesine yönelik yumuşak doku mobilizasyonundan oluştu. ${ }^{15,16} \mathrm{Bu}$ manuel terapi yöntemleri skapulanın toraks kafesi içerisinde biyomekanik olarak hareketini fasilite etmek için kullanıldı. 6 hafta süren manuel terapi uygulamalarından sonra skapula alt ucunda ve omuz ön kısmındaki ağrının ve 6. ay değerlendirmesinde serratus anterior kas kuvvetinin artmasına da bağlı olarak skapular kanatlaşmanın belirgin şekilde azaldığı görüldü. 
Olgumuzda omuz internal ve eksternal kas kuvvetinin tüm zamanlarda arttığı görüldü. Skapulohumeral ritim düşünüldüğünde, bu sonuçların skapula kinematiğinin değişiminden kaynaklı olabileceği düşünülebilir. ${ }^{17}$ Skapular hareketin üç boyutlu kinematik analizle değerlendirilmesi bu çkarımı kuvvetlendirebilirdi. Olgumuzda gözlemsel skapula değerlendirmesi limitasyondur. Ek olarak hem skapula alt ucunda hem de omuz ön bölgesindeki ağrının azalması omuz internal ve eksternal kas kuvvetindeki artışı açıklayabilir. Literatürde kassal kuvvet ile ağrı arasındaki negatif ilişki bilinmektedir. ${ }^{18}$

Olgumuzda omuz aktif eklem pozisyon hissindeki sapmanın tüm zamanlarda azaldığı ve patolojik sınırın altına düştüğ ü görüldü. ${ }^{19} \mathrm{Bu}$ sonuç ağrının azaltılması, omuz internal ve eksternal kas kuvvetinin artışı kas iğciğinden gelen afferent duyunun artmasından kaynaklı olabileceğini gösterebilir.

\section{Sonuç}

$\mathrm{Bu}$ olgu sunumu klinikte nadir görülen infraserratus bursiti olan bireylerde uygulanabilecek fizyoterapi ve rehabilitasyon programı ve bu programın etkinliği hakkında fikir sağlamaktadır. Literatürde böyle bir vaka ve rehabilitasyon sürecine rastlanmaması nedeniyle, bu olgu sunumunun özgün olduğu düşünülmektedir.

\section{Teşekkür: Yok}

Araştırmacıların Katkı Oranı Beyanı: MÇ: Çalışma tasarımı, literatür araştırma, veri toplama, makale yazma; DK: Çalışma tasarımı, makale yazma; İD: Çalışma tasarımı, makale yazma.

Çıkar Çatışması: Yok.

Finans: Yok.

Etik Onay: $B u$ olgu çalışmasına katılan olgudan aydınlatılmış onam alındı.

\section{KAYNAKLAR}

1. Conduah AH, Baker CL, Baker CL Jr. Clinical management of scapulothoracic bursitis and the snapping scapula. Sports Health. 2010;2:147155.
2. Warth RJ, Spiegl UJ, Millett PJ. Scapulothoracic bursitis and snapping scapula syndrome: a critical review of current evidence. Am J Sports Med. 2015;43:236-245.

3. Lefèvre-Colau MM, Nguyen C, Palazzo C, et al. Kinematic patterns in normal and degenerative shoulders. Part II: Review of 3-D scapular kinematic patterns in patients with shoulder pain, and clinical implications. Ann Phys Rehabil Med. 2018;61:46-53.

4. Kibler WB, Sciascia A, Wilkes T. Scapular dyskinesis and its relation to shoulder injury. J Am Acad Orthop Surg. 2012;20:364-372.

5. Kuhn JE, Plancher KD, Hawkins RJ Symptomatic scapulothoracic crepitus and bursitis. J Am Acad Orthop Surg. 1998;6:267273.

6. Dzian A, Skaličanová M, Fučela I, et al. Bilateral cystic lesions of the chest wall: Presentation of scapulothoracic bursitis. Int J Surg Case Rep. 2019;54:116-119.

7. Ferreira-Valente MA, Pais-Ribeiro JL, Jensen MP. Validity of four pain intensity rating scales. Pain. 2011;152, 2399-2404.

8. Kolber MJ, Hanney WJ. The reliability and concurrent validity of shoulder mobility measurements using a digital inclinometer and goniometer: a technical report. Int J Sports Phys Ther. 2012; 7, 306-312.

9. Hazar Kanik Z, Gunaydin G, Pala OO, et al. Translation, cultural adaptation, reliability, and validity of the Turkish version of the Penn Shoulder Score. Disabil Rehabil. 2018;40:12141219.

10. McDevitt A, Young J, Mintken P, et al. Regional interdependence and manual therapy directed at the thoracic spine. J Man Manip Ther. 2015;23:139-146.

11. Petersen J, Thorborg $\mathrm{K}$, Nielsen $\mathrm{MB}$, et al. Preventive effect of eccentric training on acute hamstring injuries in men's soccer: a clusterrandomized controlled trial. Am J Sports Med. 2011;39:2296-2303.

12. Manske RC, Reiman MP, Stovak ML. Nonoperative and operative management of snapping scapula. Am J Sports Med. 2004;32:1554-1565.

13. Moseley JB, Jobe FW, Pink M, et al. EMG analysis of the scapular muscles during a shoulder rehabilitation program. Am J Sports Med. 1992;20:128-134.

14. Colado JC, Garcia-Masso X, Triplett NT, et al. Construct and concurrent validation of a new resistance intensity scale for exercise with Thera-Band ${ }^{\circledR}$ elastic bands. J Sports Sci Med. 2014;13:758-766.

15. Senbursa G, Baltaci G, Atay A. Comparison of conservative treatment with and without manual physical therapy for patients with 
shoulder impingement syndrome: a prospective, randomized clinical trial. Knee Surg Sports Traumatol Arthrosc. 2007;15:915-921.

16. Bang MD, Deyle GD. Comparison of supervised exercise with and without manual physical therapy for patients with shoulder impingement syndrome. J Orthop Sports Phys Ther. 2000;30:126-137.

17. Gaudet S, Tremblay J, Begon M. Muscle recruitment patterns of the subscapularis, serratus anterior and other shoulder girdle muscles during isokinetic internal and external rotations. J Sports Sci. 2018;36:985-993.

18. O'Sullivan PB, Burnett A, Floyd AN, et al. Lumbar repositioning deficit in a specific low back pain population. Spine (Phila Pa 1976). 2003;28:1074-1079.

19. Yang JL, Chen S, Jan MH, et al. Proprioception assessment in subjects with idiopathic loss shoulder range of motion: Joint position sense and a novel proprioceptive feedback index. J Orthop Res. 2008;26:1218-1224. 